\title{
COMPARATIVE INVESTIGATION OF RECOMBINATION CHARACTERISTICS IN PROTON AND ELECTRON IRRADIATED Si STRUCTURES
}

\author{
J. Višniakov ${ }^{\text {a }}$, E. Gaubas ${ }^{\text {a }}$, T. Čeponis ${ }^{\text {a }}$, A. Uleckas ${ }^{\text {a }}$, J. Raisanen ${ }^{\text {b }}$, and S. Vayrynen ${ }^{\text {b }}$ \\ ${ }^{a}$ Institute of Materials Science and Applied Research, Vilnius University, Sauletekio 10, LT-10223 Vilnius, Lithuania \\ E-mail: j.visniakov@post.skynet.lt,eugenijus.gaubas@ff.vu.lt \\ ${ }^{\mathrm{b}}$ Accelerator Laboratory, University of Helsinki, Pietari Kalmin katu 2, FI-00014 Helsinki, Finland
}

Received 23 February 2008; revised 14 March 2008; accepted 21 June 2008

\begin{abstract}
Comparative analysis of the carrier recombination and generation lifetime as well as reverse recovery durations (RR), dependent on electron and proton irradiation fluence, has been performed in float zone (FZ) silicon PIN diodes and wafer structures. These investigations have been devoted to determination of the dominant radiation defects and their depth distribution, to design the irradiation technology steps for PIN diodes with fast switching rates. The samples were irradiated with $2 \mathrm{MeV}$ protons and 5-10 MeV electrons with fluences in the range of $7 \cdot 10^{12}-7 \cdot 10^{14} \mathrm{p} / \mathrm{cm}^{2}$ as well as $2.4 \cdot 10^{12}-5.2 \cdot 10^{13} \mathrm{e} / \mathrm{cm}^{2}$, respectively. Carrier decay constituents and values of recombination lifetime have been evaluated by employing a microwave probed photoconductivity transient technique (MW-PC), while deep levels spectra ascribed to generation lifetime variations have been examined by exploiting capacitance deep level transient spectroscopy (C-DLTS). Recombination lifetime decreases from several microseconds to few nanoseconds in the proton irradiated $\mathrm{Si}$, while DLTS spectra show an increase of the amplitude of a DLTS peak at $170 \mathrm{~K}$ with irradiation fluence. This peak dominates within DLTS spectra where peaks at 90 , as well as at 140 and $250 \mathrm{~K}$, ascribed to vacancy attributed defects, are also present. Recombination lifetime decreases from tens to few microseconds, while vacancy ascribed defects dominate in DLTS spectra under increase of irradiation fluence for the same material irradiated with electrons. Sharply inhomogeneous depth distribution of recombination lifetime in proton irradiated samples has been revealed from the cross-sectional scans of the excess carrier lifetime measured by MW-PC technique. This indicates a formation of the $\delta$-layer of enhanced recombination in vicinity of the $p^{+}-n$ junction of PIN diodes. Meanwhile, the recombination lifetime is nearly constant within depth of the electron irradiated Si samples. These characteristics correlate rather well with reverse recovery time constants of the same PIN diodes.
\end{abstract}

Keywords: carrier lifetime, reverse recovery time, microwave probed photoconductivity, deep level transient spectroscopy, proton and electron irradiations, radiation defects

PACS: $61.72 . J i, 61.82 . \mathrm{Fk}, 72.40 .+\mathrm{w}$

\section{Introduction}

The reverse recovery time and shape of the highvoltage high-frequency PIN rectifiers directly depend on the carrier recombination lifetime in vicinity of the $p^{+}-n$ junction [1]. Also, the reverse recovery pulse shape and symmetry, defined by a softness factor, significantly pertains to location and distribution of the fast recombination centres. Additionally, an improvement of the reverse recovery characteristics as usually must be adjusted compromising with voltage drop $V_{\mathrm{F}}$ values in the forward on-stage diode, switching time, and dynamic robustness of a device. The modern technologies of the improved reverse recovery and voltage drop of the on-stage junction characteristics are based on formation of $p^{+}-\mathrm{SiGe}$ thin layers [2] and $\mathrm{SiGe} / \mathrm{Si}$ heterojunctions [3] together with mosaic ohmic $p^{+}-n^{+}$ region $[1,3]$, by exploiting solid-state delayed breakdown (DBD) with plasma closing switch [4]. The reverse recovery nonlinearities can also be important [5]. The compromise between the reverse recovery time and voltage drop of the forward on-stage junction can be achieved by formation either of merged PIN $\left(p^{+}-n-\right.$ $n^{+}$structure) and Schottky diodes or hybrid structures of soft-recovery and punch-through diodes. Together with the state-of-the-art technologies, the gold and platinum in-diffusion $[1,6]$ as well as radiation techniques $[7,8]$ are most widely employed for industrial fabrication of the commercial high-voltage high-frequency diodes. Irradiation technologies are usually based on formation of the nearly homogeneous profiles of defects or on combination of the sharp/smooth distribution 
of recombination centres induced by proton/electron beams.

In this work, a comparative examination of the carrier lifetime as well as reverse recovery time (RRT) constants has been performed on FZ silicon PIN diodes and wafer structures to identify the optimal technological steps for formation by irradiations of a $\delta$-layer of the enhanced recombination. The samples were irradiated with $2 \mathrm{MeV}$ protons and 5-10 MeV electrons with fluences in the range of $7 \cdot 10^{12}-7 \cdot 10^{14} \mathrm{p} / \mathrm{cm}^{2}$ as well as $2.4 \cdot 10^{12}-5.2 \cdot 10^{13} \mathrm{e} / \mathrm{cm}^{2}$, respectively, to achieve the RRT values desirable for commercial PIN diodes. To determine the dominant radiation defects, which can be subjected to govern the recombination and switching rates, and to reveal their optimal depth distribution in designing the irradiation technology steps for PIN diodes, the concerted investigations have been performed by employing a microwave probed photoconductivity transient technique (MW-PC), capacitance deep level transient spectroscopy (C-DLTS), and $\mathrm{RRT} / V_{\mathrm{F}}$ measurements. Depth distribution of the recombination lifetime has been controlled by the crosssectional scans of the excess carrier lifetime by using MW-PC technique.

It has been found that depth-integrated recombination lifetime decreases from several microseconds to few nanoseconds in the proton irradiated Si. The DLTS spectra show an enhancement of a DLTS peak at $170 \mathrm{~K}$. Synchronously, the peaks at 90, 140, and $250 \mathrm{~K}$ are also observed in the DLTS spectrum. The latter are routinely ascribed to vacancy defects in the irradiated $\mathrm{Si}$. The amplitude of the $170 \mathrm{~K}$ peak increases significantly with irradiation fluence. Sharply inhomogeneous depth distribution of recombination lifetime in proton irradiated samples has been revealed from the cross-sectional scans of the excess carrier lifetime in agreement with a formation of the $\delta$-layer of enhanced recombination in vicinity of the $p^{+}-n$ junction of PIN diodes. A slower recombination lifetime decrease in the range from tens to few microseconds has been obtained for the same material irradiated with electrons. The recombination lifetime is nearly constant within depth of the electron irradiated Si samples. The vacancy ascribed $\mathrm{V}-\mathrm{O}$ defect dominates in DLTS spectra under increase of electron irradiation fluence. These characteristics correlate rather well with reverse recovery time constants of the same PIN diodes. It has been deduced from the combined analysis of the mentioned characteristics that point radiation defects dominate in the electron beam and low fluence proton irradiated Si material. However, the cluster type defects prevail in heavily proton irradi- ated material, as revealed from evolution of the DLTS spectra with fluence. The introduction rates of different point defects have been also found to be dependent on the fluence range. Competition of various defects and contradiction between diminishing of the recombination lifetime and the enhancement of the voltage drop in the on-stage junction make one consider that irradiation technology must be fine-tuned to optimize the switching characteristics of the PIN diodes.

\section{Samples and irradiations}

Two sets of samples have been examined. The first one is a collection of industrial $n-n^{+}$substrates exploited for fabrication of PIN diodes and irradiated with different fluences of $1.9-2 \mathrm{MeV}$ protons, to examine the depth integrated and depth distributed lifetime variations by contact-less technique of MW-PC. The depth integrated carrier lifetime values in the initial non-irradiated substrates have been measured by using an iodine-ethanol surface passivation, to determine a baseline of the bulk attributed recombination lifetime. The second batch consists of the standard industrial PIN diodes fabricated within technological route of the "Vilniaus Ventos Puslaidininkiai" production and proton irradiated with the same regime. The latter samples have been employed to investigate the C-DLTS, RRT $/ V_{\mathrm{F}}$, $I-V / C-V$ characteristics as well as MW-PC crosssectional scans within diode structures.

The proton irradiations were performed by using a proton accelerator at Helsinki University. The irradiations were arranged to form a $\delta$-layer of the enhanced recombination within either $n$-layer of substrates or $n$-base, i. e. $i$-layer of PIN diodes. A depth-position of the $\delta$-layer relatively to a $p^{+}-n$ junction was varied by fixing an energy of proton beam. The irradiation regimes of the $n-n^{+}$substrates and metal $-p^{+}-n-$ $n^{+}$-metal structures were made by TRIM (Transport of Radiation in Matter) application, to estimate in advance a location of $\delta$-layer. A TRIM simulated profile within PIN diode structure is illustrated in Fig. 1. Position of the $\delta$-layer was controlled by MW-PC crosssectional scan profiling of the carrier lifetime in the post-irradiation state of material. Density of radiation defects was varied by changing irradiation fluence in the range of $7 \cdot 10^{12}-7 \cdot 10^{14} \mathrm{p} / \mathrm{cm}^{2}$.

Complementary, the same diode structures were irradiated with 5-10 MeV electrons, to compare and to estimate an impact of the point and extended defects. The latter irradiations were implemented with electron fluences in the range of $2.4 \cdot 10^{12}-5.2 \cdot 10^{13} \mathrm{e} / \mathrm{cm}^{2}$ to over- 


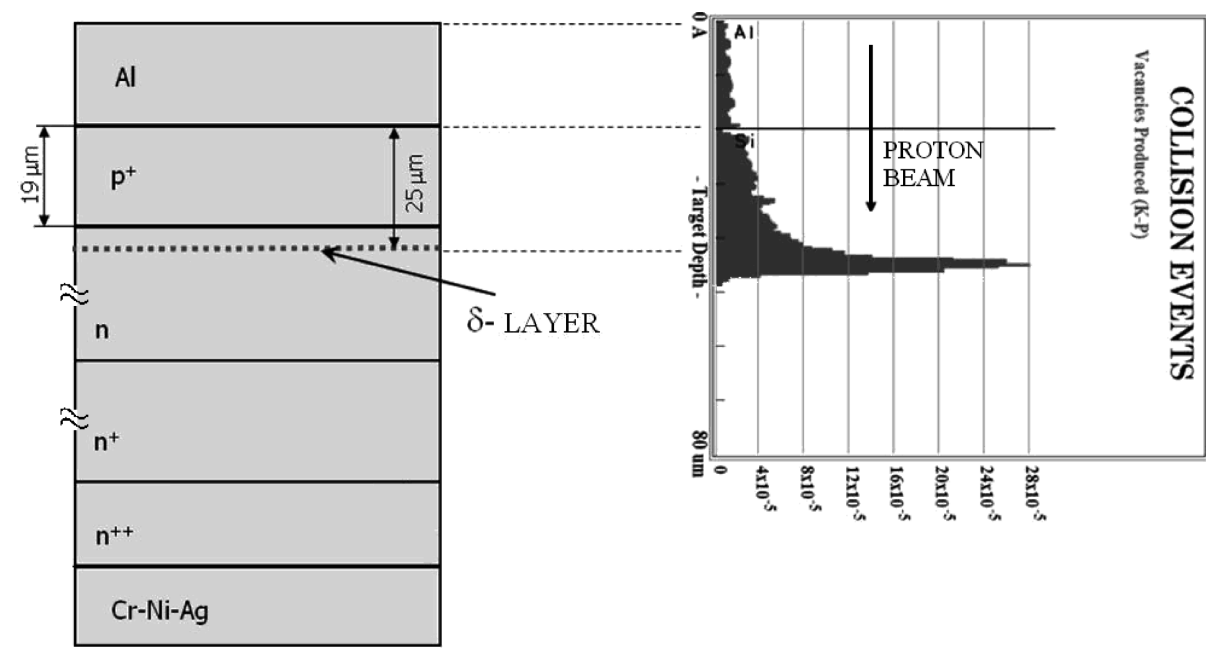

Fig. 1. Formation of a $\delta$-layer of the enhanced recombination within an $i$-layer of the PIN diode structure under $2 \mathrm{MeV}$ proton irradiation simulated by TRIM.

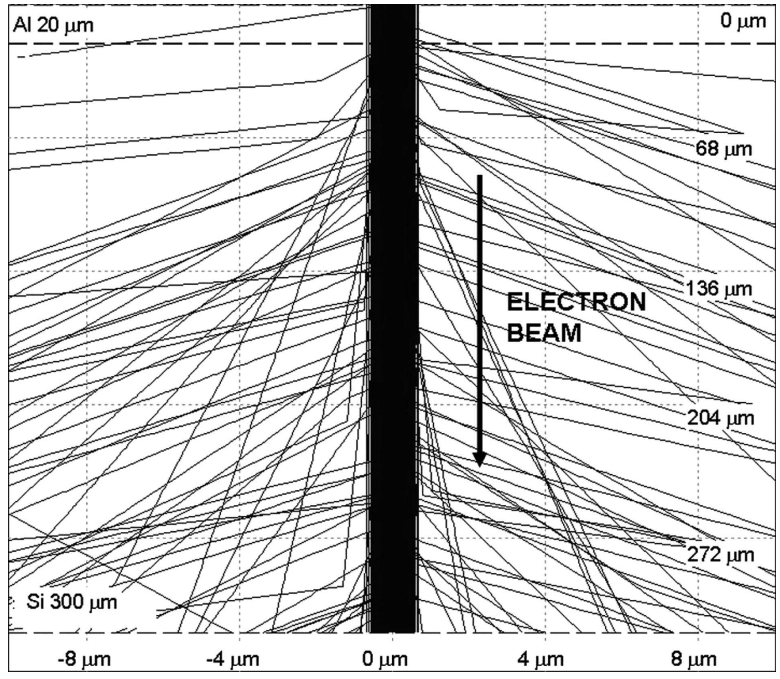

Fig. 2. Defect formation within $300 \mu \mathrm{m}$ thick Si structure under $5 \mathrm{MeV}$ electron irradiation simulated by CASINO-2X code.

lap the range of defect densities induced by electron and proton beams. Distribution of radiation defects induced by $2 \mathrm{MeV}$ electron beam, simulated by using the CASINO-2X software, is shown in Fig. 2. Already the $2 \mathrm{MeV}$ energy electrons run through the entire depth of a wafer of $300 \mu \mathrm{m}$ thickness. From a comparison of defect distributions in Figs. 1 and 2, it is evident that the main damage under proton irradiation is localized within a stopping range of protons, while electrons form defects rather homogeneously within bulk of the structure.

\section{Measurement techniques and instruments}

Excess carrier decays were examined by MW-PC technique [9-11]. Excess carriers were generated by a solid-state microchip laser operating at $1062 \mathrm{~nm}$ wavelength with pulses of $500 \mathrm{ps}$ and beam diameter of $60 \mu \mathrm{m}$. A single-mode fibre excitation with beam of 3-10 $\mu \mathrm{m}$ dimensions was exploited for excitation in cross-sectional scan regime. A pulsed excited area of the sample was probed with microwaves at $22 \mathrm{GHz}$ by using either a slit of $120 \mu \mathrm{m}$ for depth integrated lifetime measurements or a needle-tip antenna for crosssectional scans in order to obtain a high spatial resolution. Excess carrier decay transients were recorded by a digital oscilloscope TDS-5104 with time resolution of $1 \mathrm{~ns}$.

The C-DLTS measurements together with lifetime studies were performed to identify carrier trapping centres [12]. DLTS spectra were recorded by employing a commercial spectrometer DLS-82E.

$\mathrm{RRT} / V_{\mathrm{F}}$ measurements were carried out by an industrial TD2050 tester. Reverse recovery time $\tau_{\mathrm{RR}}$ in diodes is determined at 10 or $25 \%$ level of the reverse recovery current $I_{\mathrm{RR} \max }$ value. A forward current with pulse duration of $30 \mu \mathrm{s}$ can be varied in the range of $0.5-$ 15 A. Current drop rate $\mathrm{d} I / \mathrm{d} t$ is varied in the range of $10-50 \mathrm{~A} / \mu \mathrm{s}$. This tester is designed to measure the $\tau_{\mathrm{RR}}$ values in the range from $50 \mathrm{~ns}$ to $4 \mu \mathrm{s}$.

\section{Results and discussion}

Several components within the depth integrated carrier decay transients have been identified and measured in pieces of $n$-Si wafer substrates. Transients containing a short initial stage together with a convex shape constituent in the carrier density relaxation mid-stage and exponential asymptote indicate that carrier diffu- 


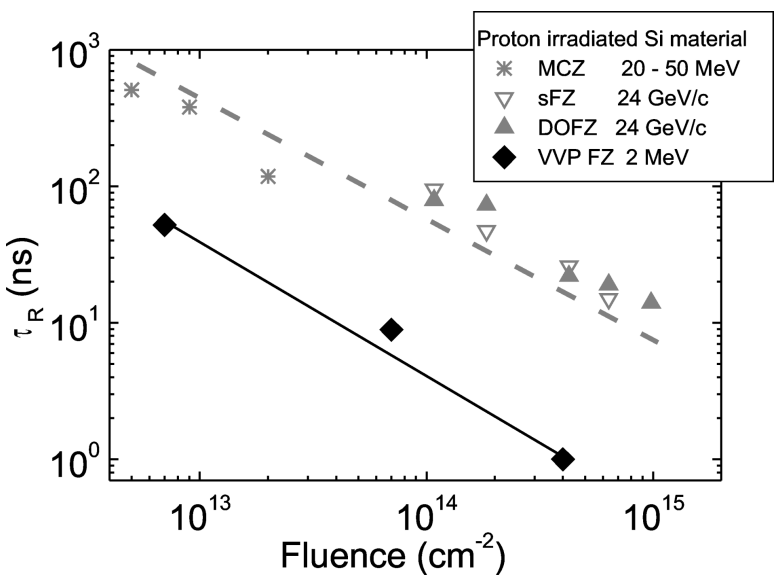

Fig. 3. Carrier recombination lifetime as a function of the irradiation fluence obtained in different $n$-Si materials ( $M C Z$ marks Czochralski grown with magnetic field, $s F Z$ marks CERN standard float zone, $D O F Z$ marks diffusion oxygenated float zone, $V V P F Z$ marks float zone moderately doped) impacted by $20 \mathrm{MeV}-24 \mathrm{GeV}$ penetrative and $2 \mathrm{MeV}$ stopped within diode protons.

sion towards $\delta$-layer of enhanced recombination can be significant. A drop rate of the initial and asymptotic single-exponential decay components increases with proton irradiation fluence. The recombination lifetime values extracted from these transients are plotted in Fig. 3 as a function of $2 \mathrm{MeV}$ protons irradiation fluence. Fluence dependent lifetime variations for $2 \mathrm{MeV}$ protons are compared in Fig. 3 with such a dependence obtained for the FZ $n$-Si samples of the same thickness irradiated with penetrative protons of $50 \mathrm{MeV}-24 \mathrm{GeV}$ energies. For the latter case, transients are usually obtained to be a concave shape and single-exponential at room temperature.

Values of the excess carrier recombination lifetime $\tau_{\mathrm{R}}$ in the $\mathrm{FZ} n$-Si irradiated with $2 \mathrm{MeV}$ protons are significantly decreased relatively to that before irradiation. The recombination lifetime decrease is close to linear with enhancement of $2 \mathrm{MeV}$ proton irradiation fluence, as can be seen in Fig. 3. However, lifetime in the latter dependence is obtained to be considerably shorter than those measured after irradiation with penetrative protons and neutrons [13] of the same fluence. This result corroborates that radiation damage is more efficient within a stopping range of $2 \mathrm{MeV}$ protons than that obtained under irradiation with penetrative hadrons.

A profile of recombination lifetime variations, measured by MW-PC cross-sectional scans, within depth of $2 \mathrm{MeV}$ proton irradiated $n$-Si wafer is illustrated in Fig. 4(a) for irradiation fluence of $4 \cdot 10^{14} \mathrm{p} / \mathrm{cm}^{2}$. This profile correlates rather well with that of defect introduction profile simulated by TRIM. A sharp step behind the stopping range of $2 \mathrm{MeV}$ protons indicates a posi- tion of $\delta$-layer a little bit smoothed by the excess carrier diffusion towards the range of enhanced recombination. The inhomogeneous profile of recombination lifetime in the $2 \mathrm{MeV}$ proton irradiated $n$-Si layer is very different from the flat one obtained within the thickness of FZ $n$-Si wafers irradiated with the penetrative protons, as determined by MW-PC cross-sectional scans. Also, a homogeneous lifetime distribution profile within sample depth is inherent for the $5-10 \mathrm{MeV}$ electron irradiated samples. The recombination lifetime profiling proves a possibility to design rather well the positioning of $\delta$-layer within diode structure by varying the energy of proton beam. An additional irradiation with penetrative electrons can be employed for a formation of the "tail" layer of a diode base. However, absolute values of recombination lifetime in $2 \mathrm{MeV}$ proton irradiated FZ $n$-Si are very different (shorter by about an order of magnitude) from that estimated for a fixed irradiation fluence by employing the defect introduction rates determined for penetrative particles. Additionally, the absolute values obtained in substrate samples are shorter than those extracted from the recombination lifetime profiling in diode structures (Fig. 4(b)). This difference could result from separation of the minority / majority excess carrier diffusion-recombination flows towards a $\delta$-layer by diode junctions. Thus, recombination lifetime absolute values and their profiles should be calibrated from fluence dependences illustrated in Figs. 3 and 4 for definite diode structure and protons energy. In these experiments, no significant difference was obtained between the lifetime values measured for the same fluence in 1.9 and $2 \mathrm{MeV}$ proton irradiated samples, except the position of a $\delta$-layer. However, there is some uncertainty due to simultaneous action of several radiation induced trapping / recombination centres which differ in their introduction rates and type.

Competition and dominance of definite defects in different fluence ranges can be observed even when only point defects are induced by a high energy electron beam, as illustrated in Fig. 5(a). Defect introduction rate, routinely estimated as a slope of a reciprocal lifetime-fluence plot in a linear scale, declines observably (Fig. 5(a)) from a single line in the range of elevated fluences, as obtained in the same (i. e. exploited for $2 \mathrm{MeV}$ proton irradiations) structure diodes. Meanwhile, the absolute lifetime values obtained at a fixed fluence are significantly different (Figs. 3, 4, and 5(b)) when comparing data for FZ $n$-Si diodes irradiated by high energy electrons and protons. This indicates that type, density, and dominance of the radiation induced defects change with irradiation energy, fluence, and par- 


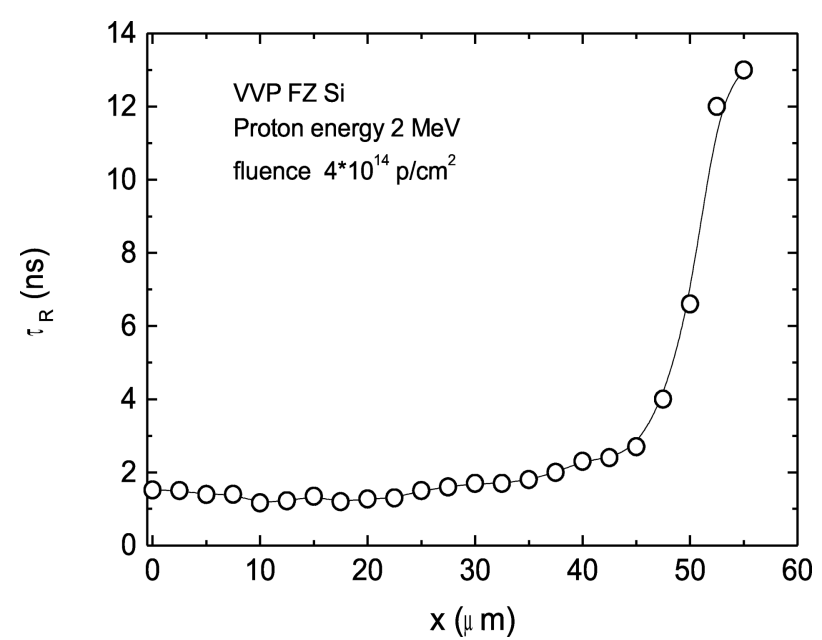

(a)

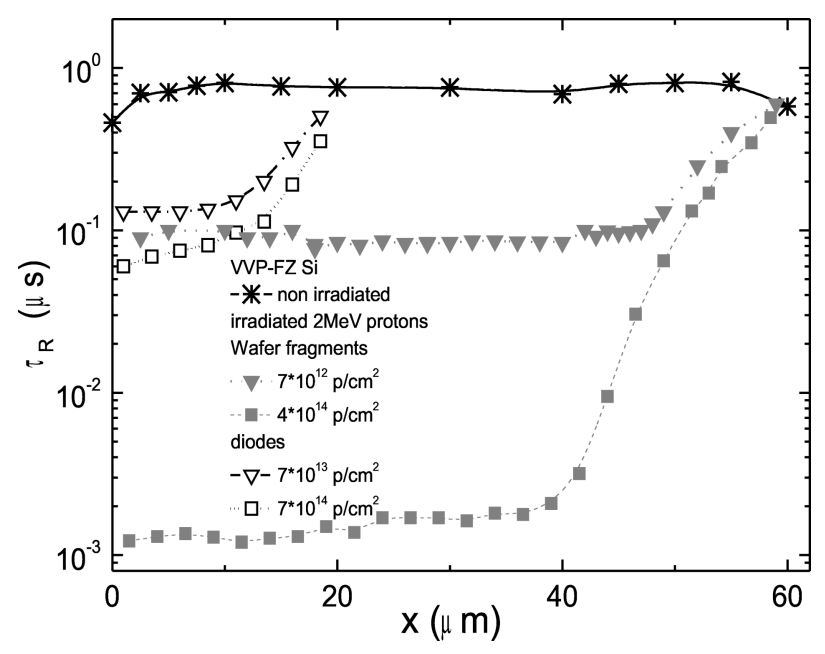

(b)

Fig. 4. (a) Recombination lifetime in-depth variation within $n$-Si substrate layer irradiated with $2 \mathrm{MeV}$ protons and $4 \cdot 10^{14} \mathrm{p} / \mathrm{cm}^{2}$ fluence, and (b) comparison of the absolute values of recombination lifetime and its depth-profiles measured by MW-PC cross-sectional scans in $n$-Si

layer of substrate as well as of diode base irradiated by $2 \mathrm{MeV}$ proton beam at various fluences relatively to non-irradiated material.

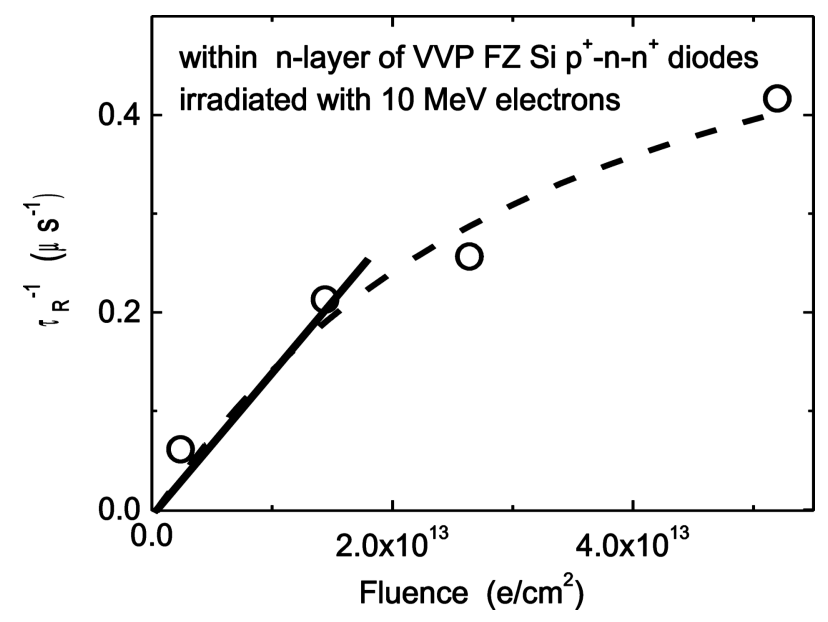

(a)

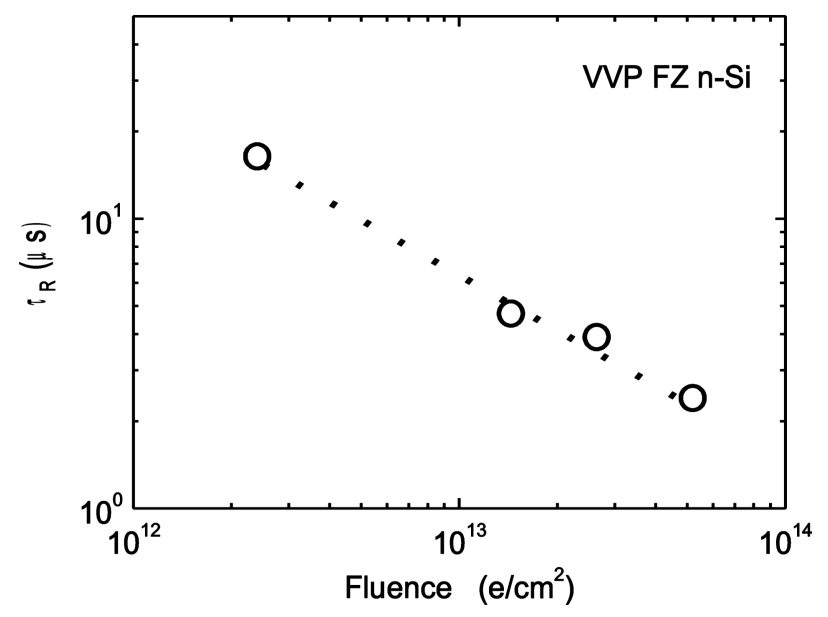

(b)

Fig. 5. (a) Estimation of the recombination defect introduction rate from a slope in the $\tau_{\mathrm{R}}^{-1}$ versus fluence dependence in $n$-base of Si diodes under electron beam irradiation and (b) the absolute values of the recombination lifetime dependent on $10 \mathrm{MeV}$ electron irradiation fluence within diode base.

ticle species. Therefore, defect introduction rate parameters and their role [12] should be carefully evaluated to design the RRT characteristics by irradiation technologies.

A comparison of parameters of the dominant generation centres, induced by $10 \mathrm{MeV}$ electron and $2 \mathrm{MeV}$ proton beams at close irradiation fluences as determined by C-DLT spectroscopy, is presented in Fig. 6. Three main DLTS peaks at 90, 140, and $250 \mathrm{~K}$ have been obtained for both electron and proton irradiated diodes at the same lock-in filtering and carrier injection parameters. These peaks are well-known in literature [14] as the ones caused by radiation defects and ascribed to vacancy related centres. The peaks are denoted by a widely accepted signature in Fig. 6, namely, as manifestation of a vacancy-oxygen complex and divacancy of $=/-$ as well as $-/ 0$ charged states, respectively. Activation energy of the latter centres has been evaluated from the Arhenius plots and found to be of $0.18 \pm 0.02$, $0.24 \pm 0.01$, and $0.43 \pm 0.02 \mathrm{eV}$, respectively. The DLT signal amplitudes of the 90 and $140 \mathrm{~K}$ peaks, obtained in diodes irradiated with $10 \mathrm{MeV}$ electrons and $2 \mathrm{MeV}$ protons, are also of close values indicating the nearly same densities of $\mathrm{V}-\mathrm{O}$ and $\mathrm{V}_{2}^{=/-}$defects. Density of the $\mathrm{V}_{2}^{-/ 0}$ defects is found to be larger in proton irradiated samples, as deduced from the peak amplitudes. The main difference between the diodes irradiated with $10 \mathrm{MeV}$ electrons and $2 \mathrm{MeV}$ protons is revealed by ap- 


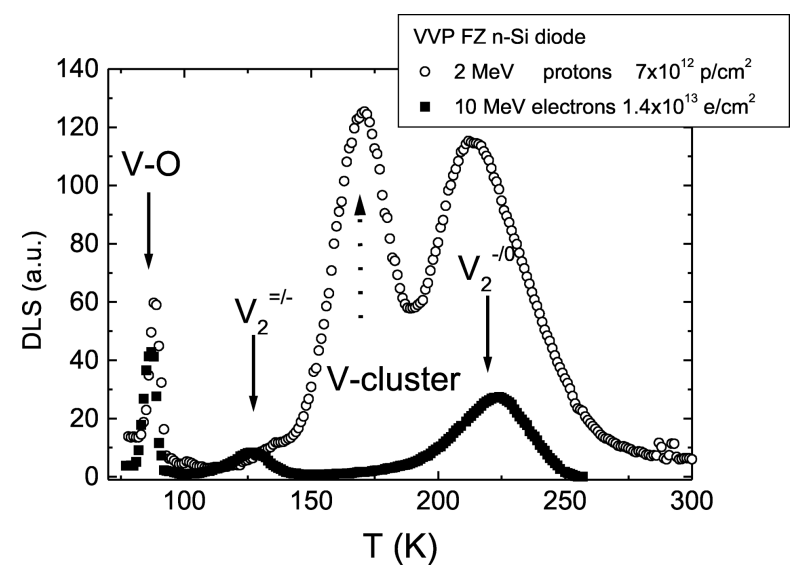

Fig. 6. Comparison of the DLTS spectra measured in diodes irradiated with $10 \mathrm{MeV}$ electrons and $2 \mathrm{MeV}$ protons of nearly the same fluence (around $10^{13} \mathrm{~cm}^{-2}$ ).

pearance of an additional DLTS peak at around $170 \mathrm{~K}$ temperature. This peak was observed in the hadron heavily irradiated Si detectors $[15,16]$ and debated as a feature due to either inter-centre recombination [15] or cluster type defects [16]. A position of the latter peak in between $\mathrm{V}_{2}^{=/-}$and $\mathrm{V}_{2}^{-/ 0}$ peaks of DLTS spectrum and its large amplitude gives a hint to vacancy clusters, as tentatively assumed in this rough analysis.

Evolution of the DLTS spectra in diodes irradiated by $2 \mathrm{MeV}$ protons with enhancement of irradiation fluence is illustrated in Fig. 7. Measurements and analysis of the evolution of spectra are complicated due to an increase of the leakage current with irradiation fluence and variations of the effective doping in the range of the highest fluences. This impedes the estimation of defect density. However, rather symmetric shape of the DLTS peaks affords a qualitative analysis of the dominant centres. For this reason, the amplitudes within a single spectrum are normalized to the strongest peak at $170 \mathrm{~K}$ in Fig. 7. Then, it can be clearly observed that peaks attributed to $\mathrm{V}-\mathrm{O}, \mathrm{V}_{2}^{=/-}$, and $\mathrm{V}_{2}^{-/ 0}$ defects fade away with enhancement of proton fluence and a single centre with inherent DLTS peak at $170 \mathrm{~K}$ prevails in the carrier capture / emission processes. This implies a conglomeration of the point defects, where the density increases and the distance between defects diminishes with the enhancement of fluence. As an alternative, the DLTS peak at $170 \mathrm{~K}$ can also be ascribed to hydrogen attributed defects with an increase of implantation fluence. This issue can be resolved by resorting to the annealing procedures. The latter investigations are in progress, and results will be published elsewhere.

Fluence and on-stage current $I_{\mathrm{F}}$ dependent variations of the diode reverse recovery time $\tau_{\mathrm{RR}}$ are presented in Fig. 8 for $2 \mathrm{MeV}$ proton and $10 \mathrm{MeV}$ electron irradi-

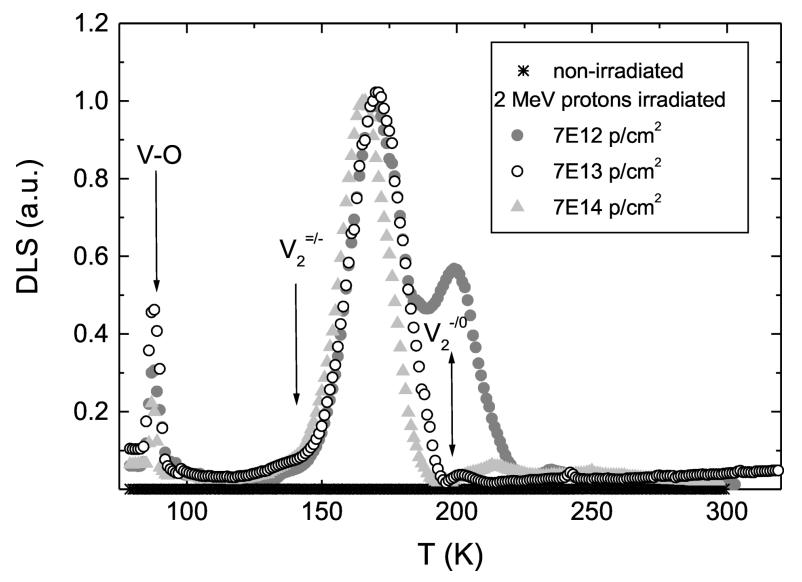

Fig. 7. Evolution of DLTS spectra in diodes irradiated by $2 \mathrm{MeV}$ protons with enhancement of irradiation fluence. Amplitudes within a single spectrum are normalized to the strongest peak at $170 \mathrm{~K}$. Structure of the spectra obtained in the $2 \mathrm{MeV}$ proton irradiated diodes is shown on the background of the DLS signal in the non-irradiated material.

ated devices. It can be noticed that $\tau_{\mathrm{RR}}$ decreases with fluence for the $2 \mathrm{MeV}$ proton irradiated diodes. The absolute $\tau_{\mathrm{RR}}$ values are close to those obtained for carrier recombination lifetime (Figs. 3, 4) only in diodes irradiated with the highest fluences for all the $I_{\mathrm{F}} \mathrm{s}$. The obtained $\tau_{\mathrm{RR}}$ values are rather large at increased $I_{\mathrm{F}}$ currents for relatively low and moderate fluences. This can be explained by importance of the carrier diffusion gradients towards a $\delta$-layer within a diode base. Also, the $\tau_{\mathrm{RR}}-I_{\mathrm{F}}$ dependences can result from increase of the excess carrier recombination lifetime with carrier density within frame of a simple Schockley-Read-Hall (S-RH) statistics through a dominant centre. The cluster type defects are suitable as candidates for a dominant centre. Qualitatively the same $\tau_{\mathrm{RR}}-I_{\mathrm{F}}$ function was obtained for electron irradiated diodes. However, a significant increase of the $\tau_{\mathrm{RR}}$ is only observed at the lowest densities of centres (as deduced from the DLTS spectra in Fig. 6). Homogeneous profile of $10 \mathrm{MeV}$ electron beam induced defects excludes an impact of the carrier diffusion gradients. This can also be a reason for a short $\tau_{\mathrm{RR}}$ in the electron irradiated diodes. It is easy to notice that $\tau_{\mathrm{RR}}$ is considerably shorter than the recombination lifetime values (Fig. 5) directly measured by MW-PC technique. Therefore, a diffusion component is not disturbed during reverse recovery processes in the case of electron beam induced traps.

\section{Summary}

The main features in formation of the fast recombination centres by irradiation technologies have been clari- 


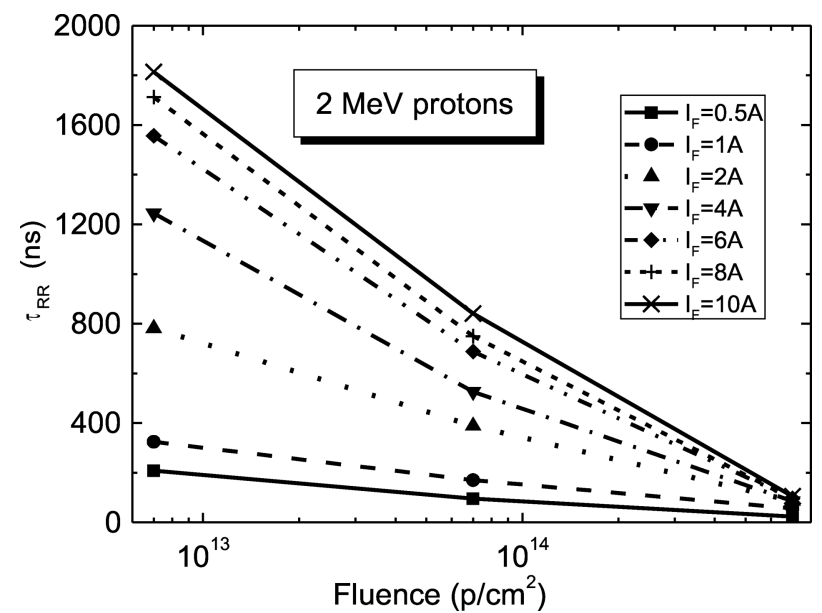

(a)

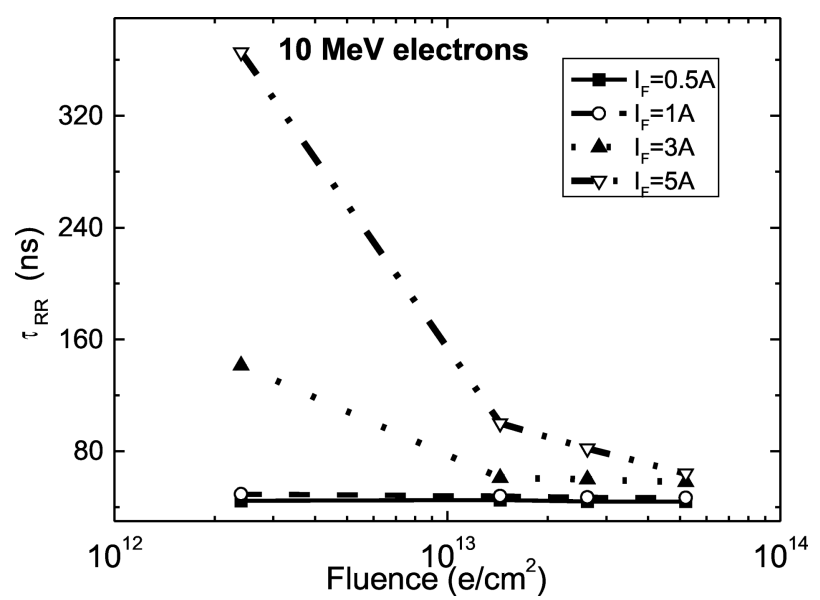

(b)

Fig. 8. Fluence dependent variations of the reverse recovery time in diodes irradiated with (a) $2 \mathrm{MeV}$ protons and (b) $10 \mathrm{MeV}$ electrons.

fied by combined analysis of MW-PC, C-DLTS, and RR characteristics, to optimize the reverse recovery charasteristics of PIN diodes.

The recombination lifetime profiling proved a possibility to design rather well a positioning of $\delta$-layer within diode structure by varying energy of proton beam in order to reach carrier lifetime values in the range of several nanoseconds. However, parameters of the defect introduction rate and their role should be carefully evaluated in designing the RRT characteristics by irradiation technologies.

Three main DLTS peaks at 90, 140, and $250 \mathrm{~K}$, ascribed to vacancy-oxygen complex and divacancy of $=/-$ as well as $-/ 0$ charged states, respectively, have been obtained for both electron and proton irradiated diodes at the same lock-in filtering and carrier injection parameters. The main difference between the diodes irradiated with $10 \mathrm{MeV}$ electrons and $2 \mathrm{MeV}$ protons is revealed by appearance of an additional DLTS peak at around $170 \mathrm{~K}$ temperature for proton irradiated structures. This implies a conglomeration of the point defects into clusters within stopping range of $2 \mathrm{MeV}$ protons, and the cluster type defects are probably dominant recombination centres at large irradiation fluences.

The $\tau_{\mathrm{RR}}$ time was found to be rather long at increased $I_{\mathrm{F}}$ currents for relatively low and moderate proton fluences due to carrier diffusion with a gradient towards the $\delta$-layer within a diode base, while homogeneous profile of $10 \mathrm{MeV}$ electron beam induced defects excludes an impact of the carrier diffusion gradients. The $\tau_{\mathrm{RR}}-I_{\mathrm{F}}$ dependences can be influenced by an increase of the excess carrier recombination lifetime with carrier density within a simple $\mathrm{S}-\mathrm{R}-\mathrm{H}$ statistics through a dominant centre.

\section{Acknowledgement}

This work was partially supported by Lithuanian State Science and Studies Foundation.

\section{References}

[1] B.Y. Baliga, Power Semiconductor Devices (PWS Publishing Company, Boston, 1995).

[2] F. Hirose, K. Kurita, Y. Takahashi, and M. Mukaida, Operation mechanism on $\mathrm{SiGe} / \mathrm{Si} / \mathrm{Si}$ PIN diodes explained using numerical simulation, Electrochem. Solid-State Lett. 8, G160-G163 (2005).

[3] M. Li, G. Yong, and W. Cai-Lin, A novel type of ultra fast and ultra soft recovery SiGe/Si heterojunction power diode with ideal ohmic contact, Chinese Phys. 13, 1114-1119 (2004).

[4] F. Zhang, W. Yu, Ch. Li, and Xi. Sun, A parametric study for $\mathrm{Si}^{+} \mathrm{nn}^{+}$diodes in picosecond closing switch applications, Solid-State Electron. 49, 399-403 (2005).

[5] R.M. de Moraes and S.M. Anlage, Unified model and reverse recovery nonlinearities of the driven diode resonator, Phys. Rev. E 68, 026201-1-9 (2003).

[6] K. Bauer, H.-J. Schulze, and F.-J. Niedernostheide, Diffusion processes for high-power devices, in: Proceedings of the 1st International Conference on Diffusion in Solids and Liquids DSL-2005 (Univ. of Aveiro, Aveiro, 2005) pp. 17-24.

[7] S.M. Kang, T.J. Eom, S.J. Kim, H.W. Kim, J.Y. Cho, and Ch. Lee, Reverse recovery characteristics and defect distribution in an electron-irradiated silicon $p-n$ junction diode, Mater. Chem. Phys. 84, 187-191 (2004).

[8] J. Vobecky, P. Hazdra, N. Galster, and E. Carroll, Freewheeling diodes with improved reverse recovery by combined electron and proton irradiation, in: Proceedings of the 8th PEMC'98 (Prague, 1998) pp. 1-4. 
[9] E. Gaubas, Transient absorption techniques for investigation of recombination properties in semiconductor materials, Lithuanian J. Phys. 43, 145-165 (2003).

[10] E. Gaubas and J. Vanhellemont, Comparative study of carrier lifetime dependence on dopant concentration in silicon and germanium, J. Electrochem. Soc. 154, H231-H238 (2007).

[11] E. Gaubas and J. Vanhellemont, Microwave and infra red light absorption studies of carrier lifetime in silicon and germanium, Solid State Phenom. 131-133, 149154 (2008).

[12] E. Gaubas, A. Uleckas, and J. Višniakov, Dose dependent variations of carrier recombination in silicon irradiated by high energy electrons, Lithuanian J. Phys. 47, 457-460 (2007).

[13] E. Gaubas, A. Kadys, A. Uleckas, and J. Vaitkus, Inves- tigation of carrier recombination in Si heavily irradiated by neutrons, Acta Phys. Pol. A 113, 837-840 (2008).

[14] S.J. Watts, Radiation induced defects in silicon, in: High Purity Silicon V, Proceedings of the 194th Meeting of Electrochemical Society, Vol. 98-13, eds. C.L. Claeys, P. Rai-Chaudhury, M. Watanabe, P. Stallhofer, and H.J. Dawson (The Electorchem. Soc., Pennington, NJ, 1998), pp. 355-370.

[15] S.J. Watts, J. Matheson, I.H. Hopkins-Bond, A. Holmes-Siedle, A. Mohammadzadeh, and R. Pace, A new model for generation-recombination in silicon depletion regions after neutron irradiation, IEEE Trans. Nucl. Sci. 43, 2587-2594 (1996).

[16] K. Gill, G. Hall, and B. MacEvoy, Bulk damage effects in irradiated silicon detectors due to clustered divacancies, J. Appl. Phys. 82, 126-136 (1997).

\title{
REKOMBINACIJOS BŪDINGŲJŲ DYDŽIŲ PALYGINAMASIS TYRIMAS PROTONAIS IR ELEKTRONAIS ŠVITINTUOSE Si DARINIUOSE
}

\author{
J. Višniakov ${ }^{\text {a }}$, E. Gaubas ${ }^{\text {a }}$, T. Čeponis ${ }^{\text {a }}$, A. Uleckas ${ }^{\text {a }}$, J. Raisanen ${ }^{\text {b }}$, S. Vayrynen ${ }^{\text {b }}$ \\ ${ }^{a}$ Vilniaus universiteto Medžiagotyros ir taikomuju mokslu institutas, Vilnius, Lietuva \\ ${ }^{\mathrm{b}}$ Helsinkio universiteto Daleliu greitintuvu laboratorija, Helsinkis, Suomija
}

\section{Santrauka}

Ištirti rekombinacijos būdingujų dydžių kitimai Si padèkluose ir dioduose, keičiant 5-10 MeV elektronų ir 1,9-2 MeV protonų integrini apšvitos srautą. Rekombinacijos parametrai tirti kombinuojant standartinę giliụjų lygmenų talpinę spektroskopiją, mikrobangų sugerties relaksacijos ir diodų perjungimo ị užtvarinę būseną trukmès matavimų metodikas. Tarpusavyje palyginus giliųuı lygmenų spektrus protonais ir neutronais apšvitintuose dariniuose, identifikuoti taškiniai ir sankaupiniai radiaciniai defektai ir jų itaka diodų perjungimo spartai. Kombinuojant ir palyginant tūryje integruotas bei priklausomai nuo gylio diodų bazèje žvalgytas krūvininkų gyvavimo trukmes, îvertinti paspartintos rekombinacijos sluoksniu sudarymo diodų bazès gilumoje parametrai. 